Vyacheslav Zhyznevskiy and Volodymyr Gumenetskiy

\title{
METACRYLONITRILE OBTAINING BY ISOBUTYLENE, TERT- AND ISOBUTYL ALCOHOLS OXIDATIVE AMONOLYSIS
}

Received: December 12, 2008

Lviv Polytechnic National University

12 Bandera str., 79013 Lviv, Ukraine

๑) Zhyznevskiy V., Gumenetskiy V. 2009

\begin{abstract}
Metacrylonitrile obtained by oxidative amonolysis over different oxidative catalysts has been investigated. Instead of isobutylene an alternative raw material has been investigated for the metacrylonitrile synthesis.
\end{abstract}

Key words: catalysis, metacrylonitrile, catalyst, promoter.

\section{Introduction}

It is well-known [1] that methacrylic acid (MAA), its esters (methyl methacrylate (MMA) first of all) and metacrylonitrile (MAN) are valuable monomers of chemical industry and are widely used in various branches of industry. MAN is used for the production of antifreeze rubbers, polymeric resins and additives for oils and lubricants. Amide or MAA and its esters may be obtained by MAN hydrolysis. The isobutylene oxidative amonolysis over corresponding catalysts [1] is the most rational and economic method for MAN obtaining. For instance, Bi-Mo-Ox system with different promoters is used for the propylene and isobutylene oxidative amonolysis [1]. Such multicomponent systems as mixture of $\mathrm{Co}, \mathrm{Ni}, \mathrm{Fe}$, As, $\mathrm{W}$ and Te oxides are also suggested. The search of advanced methods for the known systems and obtaining of new ones are continued in order to enhance MAN yield. In particular, the present authors with collaborators suggested $\mathrm{Fe}-\mathrm{Te}-\mathrm{Mo}-\mathrm{Ox}$ system with different promoters for the olefins oxidation, oxidative dehydration and oxidative amonolysis [2]. The process is carried out over Bi-Mo-Ox catalysts at 643-703 K and higher temperatures. The reaction time is prior to $6 \mathrm{~s}$ depending upon the catalyst activity. Such time provides the olefin conversion till $80 \%$ with the selectivity by MAN about $80-85 \%$ [1]. $-\mathrm{HCN}, \mathrm{CH}_{3} \mathrm{~N}$ and $\mathrm{CO}+\mathrm{CO}_{2}$ are the by-products, where two former products are commercial ones. This article deals with the investigations of catalysts which are more effective than Bi-Mo-Ox systems.

\section{Experimental}

The procedures of catalysts preparing and experimental methods of products analysis are presented in [3].

At first $\mathrm{Mo}_{12}-\mathrm{Sb}_{1,0}-\mathrm{O}_{\mathrm{x}}$ catalytic system which was effective for isobutylene oxidation to metacrolein (MA) was investigated. It is known from literature that Mo-Sb-Ox catalysts with different additives have relatively high selectivity at the oxidation of isobutylene to MA [2] and tellur oxides increase their activity and selectivity [4]. Therefore, first of all we investigated Mo-Sb-Ox catalyst with tellur. It has been established that $\mathrm{Mo}_{12} \mathrm{Sb}_{1,0} \mathrm{Te}_{1,0}$ is the most optimal catalyst by the selectivity of MAN obtaining. At isobutylene oxidative amonolysis over such catalysts a great amount of MA apart from MAN formation is formed. Sometimes MA yield exceeds MAN yield. Since MA is an intermediate product of MAN formation, these catalysts have small effeciency at the reaction of MA amonolysis. For instance, at $733 \mathrm{~K}$ under experimental conditions (flow reactor with the impulse feed of the reaction mixture of the following composition (mol \%): $i \mathrm{C}_{4} \mathrm{H}_{8}-2 ; \mathrm{O}_{2}-5 ; \mathrm{NH}_{3}-3$ in helium; contact time is $2.4 \mathrm{~s}$ ) the isobutylene conversion is $43 \%$, the selectivity by MA is $49.5 \%$ and $44.6 \%$ - by MAN; $\mathrm{CO}+\mathrm{CO}_{2}$ is the rest. Thus, in spite of the fact that these catalysts are sufficiently effective at the isobutylene oxidation into MA, they cannot be catalysts for the isobutylene oxidative amonolysis. The change of process conditions does not result in the MAN high yield.

\section{Results and Discussion}

Our investigations were aimed at the $\mathrm{Fe}-\mathrm{Te}-\mathrm{Mo}-\mathrm{Ox}$ catalytic system which has also high efficiency at the isobutylene oxidation into MA. First of all we investigated the effect of active components $\mathrm{pH}$ precipitation upon the catalytic properties of the system. Solution $\mathrm{pH}$ was changed from the neutral value $(\mathrm{pH}=7)$ to alkali value 
$(\mathrm{pH}=12)$ and acid value $(\mathrm{pH}=1)$. It has been established that under above-mentioned conditions at $613 \mathrm{~K}$ and contact time $2.4 \mathrm{~s}$ at $\mathrm{pH}=7$ the isobutylene conversion was $93.6 \%$, the selectivity by MA was $37.4 \%$ and $58.0 \%$ - by MAN. At $\mathrm{pH}=12$ the isobutylene conversion was $97.1 \%$, the selectivity $-45.7 \%$ by MA and $49.7 \%$ - by MAN. At $\mathrm{pH}=1$ the isobutylene conversion was $77.3 \%$, selectivity by MA $-40.3 \%$ and $56.7 \%$ - by MAN. Thus, MAN yields were: 93.6.0.58 $=54.3 \%($ at $\mathrm{pH}=7)$, $97.1 \cdot 0.497=48.2 \%($ at $\mathrm{pH}=12)$ and $77.3 \cdot 0.567=$ $=43.8 \%($ at $\mathrm{pH}=1)$.

One can see from above-mentioned results that the catalyst precipitated at $\mathrm{pH}=7$ is the best by MAN yield. Investigated catalysts were prepared at $\mathrm{pH}=7$ with the ratio Fe:Te:Mo = 1:0.85:1 and optimum ratio between the promoter and Mo, which was established due to the effect of promoter concentration on catalytic properties.

\subsection{The Effect of Alkaline-Earth Promoters on Fe-Te-M 0-0x Catalytic Properties}

The effect of potassium promoter on Fe-Te-Mo-Ox catalytic properties was investigated at the isobutylene oxidative amonolysis into MAN.

$\mathrm{KNO}_{3}$, which is decomposed to $\mathrm{K}_{2} \mathrm{O}$ while roasting, was used for the catalyst preparation. We choose this element because in [5] authors show that $\mathrm{KNO}_{3}$ is the best for the Fe-Te-Mo-Ox catalyst promoter by MA yield. We prepared a series of catalysts with various concentrations of the promoter (K/Mo atomic ratio was 0.01-0.5). The obtained results are presented in Fig. 1.

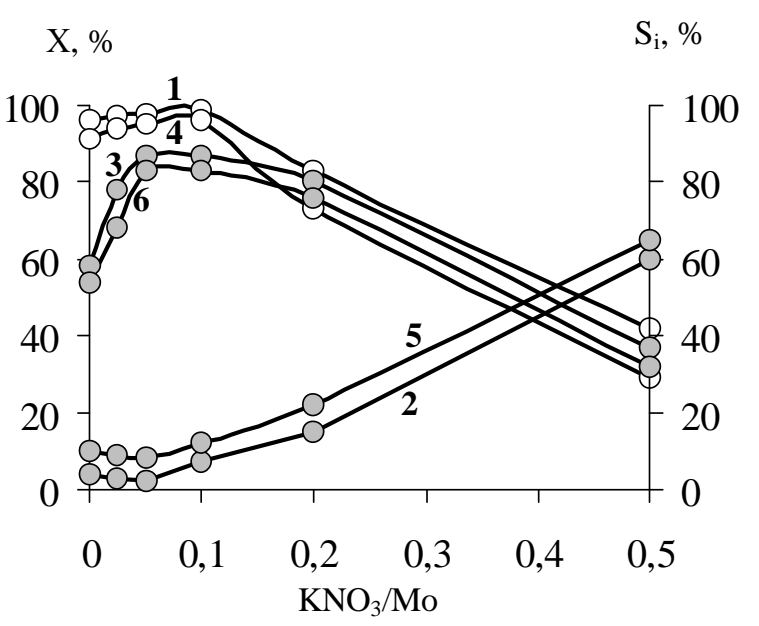

Fig. 1. The effect of $\mathrm{KNO}_{3} / \mathrm{Mo}$ ratio on the catalytic properties of the Fe-Te-Mo-Ox catalyst at the contact time of $2.4 \mathrm{~s}$ and temperatures $643 \mathrm{~K}(1,2,3)$ and $613 \mathrm{~K}(4,5,6)$. Isobutylene conversion - $\mathrm{X}_{\mathrm{iC} 4 \mathrm{H} 8}(1,4)$; selectivity by MA $\mathrm{S}_{\mathrm{MA}}(2,5)$ and selectivity by MAN $-\mathrm{S}_{\mathrm{MAN}}(3,6)$. The reaction mixture composition $(\mathrm{mol} \%): \mathrm{iC}_{4} \mathrm{H}_{8}-2 ; \mathrm{O}_{2}-5$; $\mathrm{NH}_{3}-3$. Flow rate $\left(\mathrm{V}_{\mathrm{f}}\right)$ is $0.56 \mathrm{~cm}^{3} / \mathrm{s}$, impulse volume $\left(\mathrm{V}_{\text {imp }}\right)$ is $6.2 \mathrm{~cm}^{3}$, the flow reactor with impulse feed.
One can see from Fig. 1 that the best catalyst by MAN yield is the catalyst with $\mathrm{K} / \mathrm{Mo}$ ratio equaling to 0.1 (MAN yield is $84.3 \%$ ). Almost the same yield is obtained over the catalyst with the ratio of 0.05 . It has been established that increase of the $\mathrm{K} / \mathrm{Mo}$ ratio over 0.1 decreases the olefins conversion and the selectivity by MAN but increases the selectivity by MA. When K/Mo ratio equals to 0.5 at temperature of $643 \mathrm{~K}$ olefin conversion and the selectivity by MAN decrease to 42.8 and 37.5 respectively.

The effect of temperature and contact time on the isobutylene conversion and the selectivity by products of oxidative amonolysis over optimal catalyst $\left(\mathrm{KNO}_{3} / \mathrm{Mo}=\right.$ $=0.1$ ) is represented in Table 1 . Process conditions are shown in Fig. 1.

Table 1

Dependence of isobutylene conversion and selectivity by products upon temperature and contact time over optimal by MAN yield catalyst $\left(\mathrm{KNO}_{3} / \mathrm{Mo}=\mathbf{0 . 1}\right)$

\begin{tabular}{|c|c|c|c|c|}
\hline $\mathrm{T}_{\mathrm{p}}, \mathrm{K}$ & $\mathrm{X}_{\mathrm{iC}_{4} \mathrm{H}_{8}, \%}$ & $\mathrm{~S}_{\mathrm{MA}}, \%$ & $\mathrm{~S}_{\mathrm{MAH}}, \%$ & $\mathrm{~S}_{\mathrm{CO}+\mathrm{CO}_{2}, \%}$ \\
\hline 643 & $99.2(87.7)$ & $6.8(26.3)$ & $85.0(71.9)$ & $7.1(1.7)$ \\
\hline 613 & $97.2(69.7)$ & $11.7(24.6)$ & $84.7(75.1)$ & $3.6(0.3)$ \\
\hline 583 & $94.6(32.5)$ & $16.1(33.7)$ & $82.2(66.3)$ & $1.7(-)$ \\
\hline
\end{tabular}

Note: contact time is $2.4 \mathrm{~s}$ for values without brackets and $0.6 \mathrm{~s}$ for values in brackets.

Table 2

Effect of temperature and contact time on catalytic properties of $\mathrm{Fe}-\mathrm{Te}-\mathrm{Mo}-\mathrm{Ox}$ catalyst promoted with barium nitrate $(\mathrm{Ba} / \mathrm{Mo}=0.1)$ at the isobutylene oxidative amonolysis

\begin{tabular}{|c|c|c|c|c|}
\hline $\mathrm{T}_{\mathrm{p}}, \mathrm{K}$ & $\mathrm{X}_{\mathrm{iC}_{4} \mathrm{H}_{8}, \%}$ & $\mathrm{~S}_{\mathrm{MA}}, \%$ & $\mathrm{~S}_{\mathrm{MAN}}, \%$ & $\mathrm{~S}_{\mathrm{CO}+\mathrm{CO}_{2}, \%}$ \\
\hline 583 & $97.0(47.3)$ & $11.7(28.3)$ & $86.9(71.7)$ & $1.4(-)$ \\
\hline 613 & $97.8(81.5)$ & $8.0(22.0)$ & $86.4(77.3)$ & $5.6(0.7)$ \\
\hline 643 & $99.0(94.7)$ & $6.1(16.6)$ & $86.0(80.4)$ & $8.9(3.0)$ \\
\hline
\end{tabular}

Note: contact time is $2.4 \mathrm{~s}$ for values without brackets and $0.6 \mathrm{~s}$ for values in brackets. Conditions are shown in Fig. 1 .

The increase of temperature from 583 to $643 \mathrm{~K}$ and contact time from 0.6 to $2.4 \mathrm{~s}$ increases the selectivity by MAN. Under optimal conditions $(\mathrm{T}=643 \mathrm{~K}$ and $\tau_{\mathrm{k}}=2.4 \mathrm{~s}$ ) over the better catalyst the general selectivity by MAN+MA (the latter may be returned to the reactor inlet) is $84.3+6.8=91.1 \%$. This sum equals to $88.0 \%$ over the catalyst with $\mathrm{KNO}_{3} / \mathrm{Mo}=0.05$, so the first catalyst is a better one.

The effect of barium promoter with the ratio $\mathrm{Ba} / \mathrm{Mo}=0.1$ [5] was investigated at the reaction of isobutylene oxidative amonolysis (Table 2).

Results from Table 2 show that at $\tau_{\mathrm{k}}=0.6 \mathrm{~s}$ increase of temperature increases the selectivity by MAN and decreases the selectivity by MA. At $\tau_{\mathrm{k}}=2.4 \mathrm{~s}$ both selectivities by MAN and MA decrease. The increase of 
contact time also increases the selectivity by MAN. The maximum MAN yield $(85.1 \%)$ was obtained at $643 \mathrm{~K}$ and $\tau_{\mathrm{k}}=2.4 \mathrm{~s}$. Just such conditions may be considered as optimum ones for the isobutylene oxidative amonolysis over $\mathrm{FeTe}_{0.85} \mathrm{MoOx}$ promoted by $\mathrm{Ba}\left(\mathrm{NO}_{3}\right)_{2}$. Under these conditions MA (the selectivity by MA is $6.1 \%$ ) is also presented in the reaction products, as well as MAN and total oxidation products. MA may be returned into the process. The increase of the selectivity by MAN and decrease of the selectivity by MA may be explained by the fact that MA is an intermediate product of nitrile formation. The low yield of total oxidation products may be explained by the presece of $\mathrm{NH}_{3}$ in the reaction mixture, which blocks strong acid centers of the system surface, where destructive and total oxidation of organic substrates takes place. Alkaline-earth promoter of the catalyst plays the same role.

The effect of magnesium promoter. E. Dvonchova [5] shows that at the isobutylene oxidation $\mathrm{Fe}-\mathrm{Te}-\mathrm{Mo}-\mathrm{Ox}$ catalyst promoted with $\mathrm{Mg}\left(\mathrm{NO}_{3}\right)_{2}$, which decomposes to $\mathrm{MgO}$ at heating, is the best catalyst among catalysts of such a type promoted with alkali-earth metals regarding to MA yield. We investigated the effect of $\mathrm{Mg}^{2+}$ nitrate on the catalytic properties of this catalyst at the isobutylene oxidative amonolysis. Our results are represented in Table 3.

The increase of $\mathrm{Mg} / \mathrm{Mo}$ ratio from 0.01 to 0.2 considerably increases the catalyst activity. At $583 \mathrm{~K}$ olefin conversion increases from 16.9 to $70.3 \%$. The maximum selectivity by MAN $(82.4 \%)$ is obtained at this temperature over $\mathrm{K}_{1}$ with a promoter minimum amount. However, since olefin conversion is very low (16.9\%), MAN yield is only $13.9 \%$.

The increase of temperature decreases the selectivity by MAN and increases the selectivity by MA for the majority of investigated catalysts due to the higher activation energy of MA compared with MAN. Maximum yield of MAN equals to $60.2 \%$ was obtained over $\mathrm{K}_{3}$ at $643 \mathrm{~K}$ and $\tau_{k}=2.4 \mathrm{~s}$.

In our work [6] we have shown that stable salts of alkaline-earth promoters have the higher efficiency by the yield of partial oxidation products compared with their nitrates which are decomposed into oxides at high temperatures. Therefore, it was advisable to study the effect of $\mathrm{MgSO}_{4}$ on the catalytic properties of Fe-Te-Mo-Ox catalyst and compare obtained results with the data from Table 3, where $\mathrm{Mg}\left(\mathrm{NO}_{3}\right)_{2}$ was a promoter.

The effect of $\mathrm{MgSO}_{4}$ concentration on the catalytic properties of Fe-Te-Mo-Ox at the isobutylene oxidative amonolysis at different temperatures (613-673 K) and contact times (1.2-3.6 s) is represented in Table 4 . The same effect but over the optimal by MAN yield catalyst $\left(\mathrm{MgSO}_{4} / \mathrm{Mo}=0.2\right)$ is represented in Fig. 2.

One can see from Fig. 2a that under experimental conditions MAN maximum yield $(80.5 \%)$ is achieved at $583 \mathrm{~K}$ and contact time $3.6 \mathrm{~s}$ over $\mathrm{K}_{8}$ catalyst with $\mathrm{MgSO}_{4} / \mathrm{Mo}=0.2$. It is considerably higher than over the catalyst promoted with $\mathrm{Mg}\left(\mathrm{NO}_{3}\right)_{2}$ over which the yield is only $26.9 \%$ at $583 \mathrm{~K}$ and $\tau_{\mathrm{k}}=2.4 \mathrm{~s}$. At higher temperature $(643 \mathrm{~K})$ and $\tau_{\mathrm{k}}=2.4 \mathrm{~s}$ the MAN yield is $44.4 \%$ and maximum yield obtained over $\mathrm{K}_{3}$ is $60.2 \%$, that is less by $20.3 \%$ in comparison with the catalyst promoted with $\mathrm{MgSO}_{4}$.

Thus, anion of the promoter salt also affects the catalytic properties.

The effect of temperature and contact time over the optimal catalyst promoted with $\mathrm{MgSO}_{4}$ is also represented also in Fig. 2a. At contact time of $3.6 \mathrm{~s}$ MAN yield decreases from $80.5 \%$ at $583 \mathrm{~K}$ to $45 \%$ at $673 \mathrm{~K}$.

Table 3

Effect of magnesium nitrate amount on catalytic properties of Fe-Te-Mo-Ox catalyst at the isobutylene oxidative amonolysis to the metacrylonitrile (impulse flow reactor, $V_{f}=0.56 \mathrm{~cm}^{3} / \mathrm{s} ; V_{\text {imp }}=6.2 \mathrm{~cm}^{3}$, $\tau_{k}=2.4 \mathrm{~s}$, reaction mixture composition ( $\left.\mathrm{mol} \%\right): i \mathrm{C}_{4} \mathrm{H}_{8}-2 ; \mathrm{O}_{2}-5 ; \mathrm{NH}_{3}-3$ in the helium)

\begin{tabular}{|c|c|c|c|c|c|}
\hline \multirow{2}{*}{$\mathrm{Mg} / \mathrm{Mo}$ ratio } & \multirow{2}{*}{$\mathrm{T}, \mathrm{K}$} & \multirow{2}{*}{$\mathrm{X}, \%$} & \multicolumn{2}{|c|}{ Selectivity by:, $\%$} & \multirow{2}{*}{ MAN yield, $\%$} \\
\hline & & & MA & MAN & \\
\hline \multirow{3}{*}{$0.01\left(\mathrm{~K}_{1}\right)$} & 583 & 16.9 & 17.6 & 82.4 & 13.9 \\
\hline & 613 & 41.8 & 34.9 & 64.3 & 26.9 \\
\hline & 643 & 68.3 & 49.0 & 49.0 & 33.5 \\
\hline \multirow{3}{*}{$0.02\left(\mathrm{~K}_{2}\right)$} & 583 & 31.3 & 30.8 & 69.1 & 22.3 \\
\hline & 613 & 57.7 & 47.4 & 50.7 & 29.2 \\
\hline & 643 & 84.2 & 49.8 & 47.3 & 39.8 \\
\hline \multirow{3}{*}{$0.05\left(\mathrm{~K}_{3}\right)$} & 583 & 80.0 & 49.2 & 48.5 & 38.8 \\
\hline & 613 & 97.1 & 55.1 & 40.6 & 39.4 \\
\hline & 643 & 98.4 & 32.9 & 61.2 & 60.2 \\
\hline \multirow{3}{*}{$0.1\left(\mathrm{~K}_{4}\right)$} & 583 & 64.8 & 39.0 & 59.1 & 38.3 \\
\hline & 613 & 72.2 & 40.7 & 55.2 & 40.0 \\
\hline & 643 & 98.9 & 38.1 & 54.9 & 54.3 \\
\hline \multirow{3}{*}{$0.2\left(\mathrm{~K}_{5}\right)$} & 583 & 70.3 & 61.5 & 38.2 & 26.9 \\
\hline & 613 & 93.6 & 61.6 & 37.3 & 34.9 \\
\hline & 643 & 99.1 & 49.2 & 44.9 & 44.4 \\
\hline
\end{tabular}


Table 4

Effect of $\mathrm{MgSO}_{4}$ on catalytic properties of the oxide catalyst (Fe:Te:Mo $\left.=1: 0.85: 1\right)$ at the isobutylene oxidative amonolysis (conditions are shown in Fig. 1)

\begin{tabular}{|c|c|c|c|c|c|c|}
\hline \multirow{2}{*}{$\mathrm{Mg} / \mathrm{Mo}$ ratio } & \multirow{2}{*}{$\tau_{k}$} & \multirow{2}{*}{$\mathrm{T}, \mathrm{K}$} & \multirow{2}{*}{$\mathrm{X}, \%$} & \multicolumn{2}{|c|}{ Selectivity by:, \% } & \multirow{2}{*}{ MAN yield, $\%$} \\
\hline & & & & MA & MAN & \\
\hline \multirow{9}{*}{$0.05\left(\mathrm{~K}_{6}\right)$} & \multirow{3}{*}{1.2} & 703 & 80.5 & 72.2 & 6.9 & 5.5 \\
\hline & & 673 & 71.7 & 78.6 & 24.0 & 17.2 \\
\hline & & 643 & 62.8 & 61.2 & 35.0 & 22.0 \\
\hline & \multirow{3}{*}{2.4} & 703 & 92.3 & 57.6 & 18.6 & 17.1 \\
\hline & & 673 & 80.8 & 48.8 & 36.2 & 29.2 \\
\hline & & 643 & 74.5 & 43.1 & 48.3 & 36.0 \\
\hline & \multirow{3}{*}{3.6} & 703 & 97.0 & 64.4 & 11.9 & 11.5 \\
\hline & & 673 & 95.9 & 65.0 & 14.0 & 13.4 \\
\hline & & 643 & 88.1 & 66.9 & 19.3 & 17.0 \\
\hline \multirow{9}{*}{$0.1\left(\mathrm{~K}_{7}\right)$} & \multirow{3}{*}{1.2} & 673 & 86.0 & 59.9 & 16.4 & 14.1 \\
\hline & & 643 & 74.6 & 46.3 & 40.0 & 29.8 \\
\hline & & 613 & 48.4 & 29.1 & 58.9 & 28.5 \\
\hline & \multirow{3}{*}{2.4} & 673 & 90.1 & 52.7 & 24.2 & 21.8 \\
\hline & & 643 & 88.6 & 42.3 & 43.4 & 38.4 \\
\hline & & 613 & 67.3 & 21.5 & 68.2 & 45.9 \\
\hline & \multirow{3}{*}{3.6} & 673 & 92.8 & 44.3 & 35.4 & 32.5 \\
\hline & & 643 & 90.9 & 35.2 & 50.4 & 45.8 \\
\hline & & 613 & 85.2 & 18.1 & 71.4 & 60.8 \\
\hline \multirow{3}{*}{$0.5\left(\mathrm{~K}_{9}\right)$} & \multirow{3}{*}{1.2} & 643 & 100.0 & - & 76.5 & 76.5 \\
\hline & & 613 & 82.9 & 6.9 & 67.5 & 55.9 \\
\hline & & 583 & 67.8 & 5.9 & 86.4 & 58.5 \\
\hline
\end{tabular}

Note: Results obtained over $\mathrm{K}_{8}(\mathrm{Mg} / \mathrm{Mo})$ are represented in Fig. 2
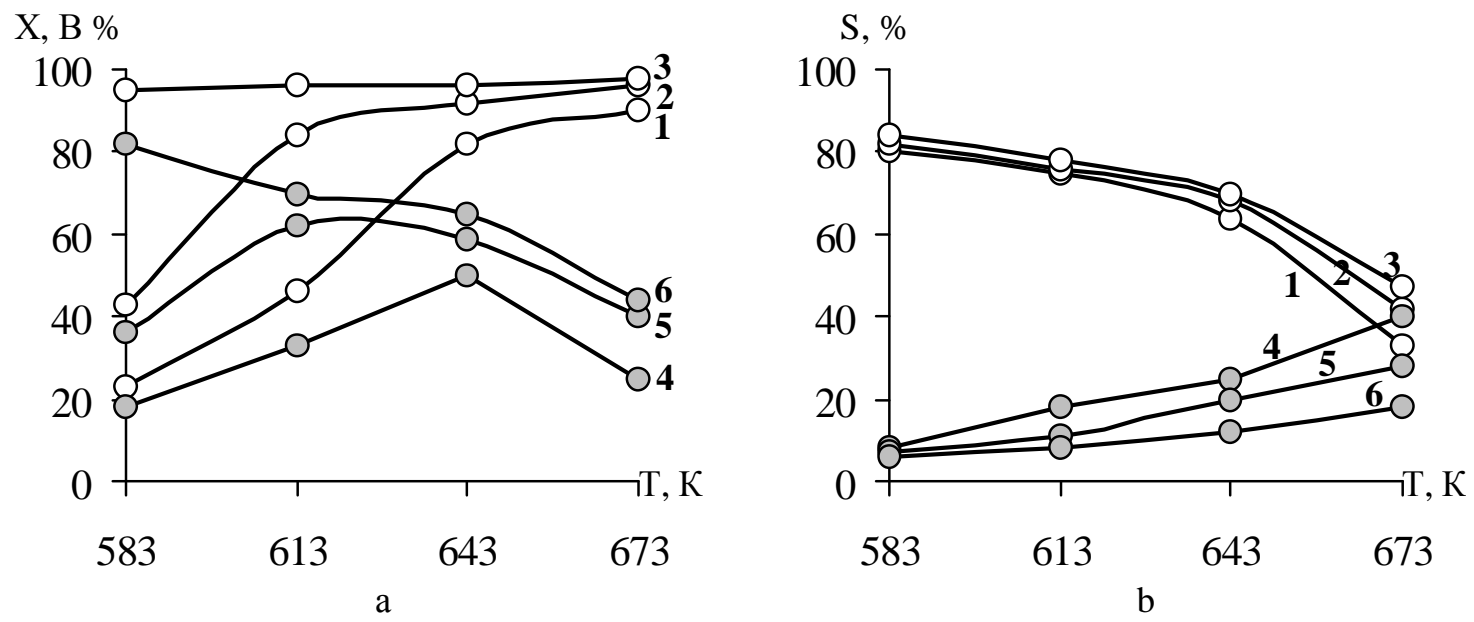

Fig. 2. Effect of temperature and contact time on the isobutylene conversion (X) and metacrylonitrile yield (B) (a) as well as on the selectivity by MA and MAN (b) over optimal Fe-Te-Mo-Ox catalyst promoted with $\mathrm{MgSO}_{4}(\mathrm{Mg} / \mathrm{Mo}=0.2)$ :

(a) isobutylene conversion (1-3), MAN yield (4-6); (b) selectivity by MAN (1-3) and by MA (4-6) at $\tau_{\mathrm{k}}=1.2 ; 2.4$ and 3.6 correspondingly. Conditions are shown in Fig. 1.

This dependence is connected, first of all, with a considerable decrease of the selectivity by MAN from 85 to $43.7 \%$ with the increase of temperature (Fig. 2b). At $\tau_{k}=1.2 \mathrm{~s}$ MAN maximum yield is observed at $643 \mathrm{~K}$ and at $\tau_{k}=2.4 \mathrm{~s}$ MAN maximum yield is practically the same $(60 \%)$ within the temperature range of $613-643 \mathrm{~K}$. The increase of temperature increases the conversion and simultaneously decreases the selectivity.
It is well-known that mobility of oxygen over the catalyst surface and surface acidity play an important role in the oxidation processes $[7,8]$. It is obvious that Fe-TeMo-Ox promotion with alkaline-earth elements, $\mathrm{Mg}^{2+}$ in particular, essentially affects the amount and nature of acid active centres. Since ammonia participates in the oxidative amonolysis, disables strong acid centres over catalyst surface during its hemosorption [2] and increases 
the process selectivity, we may assume that $\mathrm{Mg}^{2+}$ cation will act in an analogous way. Moreover, activation of $\mathrm{NH}_{3}$ molecule is necessary for MAN formation. This activation has a basic character; hence it will take place over the acid centre. So, the catalyst activity in the oxidative amonolysis reaction will depend upon the activation of olefin, $\mathrm{NH}_{3}$ and oxygen.

The mechanism of oxidative amonolysis reaction in the presence of Bi-Mo-O catalyst is discussed in [9, 10]. It is assumed that olefin activation takes place over Mo-centre due to the hydrogen atom detachment by oxygen connected with $\mathrm{Bi}$ atom and due to the formation of $\pi$-allyl compound. The latter may interacts with oxygen and form unsaturated aldehyde or unsaturated nitrile [9] if interacts with the ammonia active form. This active form $(\mathrm{NH})$ is formed due to $\mathrm{NH}_{3}$ partial oxidation [10]. At the same time $\mathrm{M}$. $\mathrm{Ai}$ [8] shows that activation of compounds with a basic character, to which both $\mathrm{NH}_{3}$ and $i-\mathrm{C}_{4} \mathrm{H}_{8}$ belong, takes place over acid centres of the catalyst surface. Thus, active and selective by the nitrile catalyst should have corresponding acid centres as well as mobile oxygen. It is obvious that oxygen activation proceeds over basic centres of the surface through electrons transfer. So, alkaline-earth $\mathrm{Mg}^{2+}$ will form such activation centres for oxygen and enhances the catalyst activity. It was shown in [2] that olefins partial oxidation proceeded by redox reaction over $\mathrm{Fe}-\mathrm{Te}-\mathrm{Mo}-\mathrm{Ox}$ catalyst. Moreover, isobutylene reaction is limited by reoxidation of the surface active centres. The catalyst maximum efficiency is observed when oxidation and reduction stages have approximately the same rates. Therefore, promoter $\left(\mathrm{Mg}^{2+}\right)$ concentration accelerating the reoxidation stage must be optimal. In our experiments the concentration responds to $\mathrm{Mg} / \mathrm{Mo}$ ratio equaling to 0.2 and optimal conditions are: temperature is $583 \mathrm{~K}$, contact time is $3.6 \mathrm{~s}$. MAN yield is $80.5 \%$ under optimal conditions. The higher efficiency of the catalyst promoted with $\mathrm{MgSO}_{4}$ compared with that promoted with $\mathrm{Mg}\left(\mathrm{NO}_{3}\right)_{2}$ may be explained by higher decomposition temperature of $\mathrm{MgSO}_{4}(1400 \mathrm{~K})$ [11]. Under experimental conditions $\mathrm{MgSO}_{4}$ is not decomposed, therefore it is presented in the system composition instead of magnesium oxide and such a fact has an essential effect on the catalyst properties.

\subsection{Investigation of Alternative Raw Material for MAN Obtaining}

It is known from patents that tert-butyl alcohol (TBA) may be alternative raw material for isobutylene at oxidation processes. At isobutylene oxidative amonolysis the best results were obtained over catalysts promoted with barium salts. Therefore we investigated the effect of barium salts $\left(\mathrm{Ba}\left(\mathrm{NO}_{3}\right)_{2}, \mathrm{BaSO}_{4}\right.$ and $\left.\mathrm{BaCl}\right)$ concentrations on the catalytic properties of $\mathrm{Fe}-\mathrm{Te}-\mathrm{Mo}-\mathrm{Ox}$ catalyst at TBA oxidative amonolysis to MAN.

The effect of $\mathrm{Ba}\left(\mathrm{NO}_{3}\right)_{2} / \mathrm{Mo}$ and $\mathrm{BaSO}_{4} / \mathrm{Mo}$ on the catalytic properties of Fe-Te-Mo-Ox at $643 \mathrm{~K}$ and $\tau_{k}=2.4 \mathrm{~s}$ is represented in Figs. 3 and 4.

One can see that MA maximum yield is achieved over the catalyst promoted with $\mathrm{Ba}\left(\mathrm{NO}_{3}\right)_{2}$ when $\mathrm{Ba} / \mathrm{Mo}$ ratio is equal to 0.1 . Over this catalyst at $643 \mathrm{~K}$ and $\tau_{\mathrm{k}}=2.4 \mathrm{~s} \mathrm{MAN}$ yield is $85.2 \%, i-\mathrm{C}_{4} \mathrm{H}_{8}$ conversion is $98 \%$, the selectivity by $\mathrm{MAN}$ is $87 \%$, by $\mathrm{MA}-8 \%$, by $\mathrm{CO}+\mathrm{CO}_{2}-5 \%$.

For the catalyst promoted with $\mathrm{BaSO}_{4}$ the ratio $\mathrm{BaSO}_{4} / \mathrm{Mo}=0.05$ is optimum by MAN yield (see Fig. 4 ). Over this catalyst $i$ - $\mathrm{C}_{4} \mathrm{H}_{8}$ conversion is $78 \%$, the selectivity by $\mathrm{MAN}$ is $80 \%$, by $\mathrm{MA}-8 \%$, by $\mathrm{CO}+\mathrm{CO}_{2}-12 \%$. MAN yield is $62.4 \%$.

If we use the catalyst promoted with $\mathrm{BaCl}_{2}$ (Table 5) the optimum ratio $\mathrm{BaCl}_{2} / \mathrm{Mo}$ is 0.1 . Over such catalyst MAN maximum yield $(87.2 \%)$ is achieved at $643 \mathrm{~K}$ and contact time of $3.6 \mathrm{~s}$. Isobutylene conversion is $98 \%$, the selectivity by MAN id $89 \%$, by $\mathrm{MA}-2 \%$, by $\mathrm{CO}+\mathrm{CO}_{2}-9 \%$.

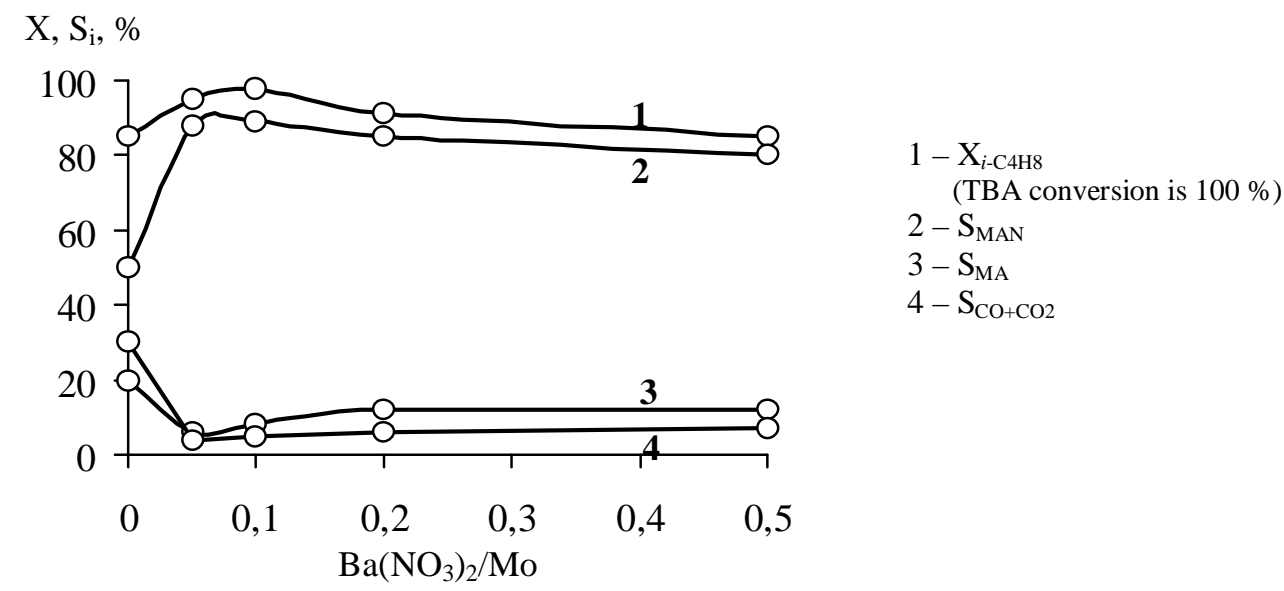

Fig. 3. Effect of $\mathrm{Ba}\left(\mathrm{NO}_{3}\right)_{2} / \mathrm{Mo}$ ratio on the catalytic properties of Fe-Te-Mo-Ox catalyst at TBA oxidative amonolysis to MAN. Temperature is $643 \mathrm{~K}$, contact time is $2.4 \mathrm{~s}$, reaction conditions are given in Table 5 . 


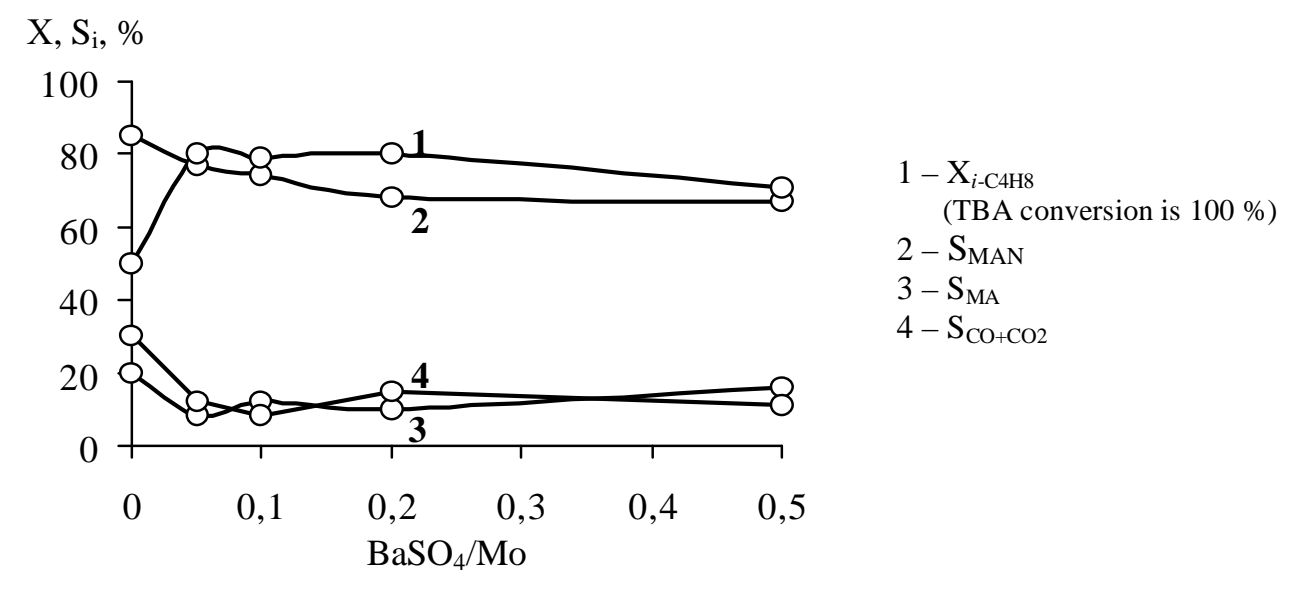

Fig. 4. Effect of $\mathrm{BaSO}_{4} / \mathrm{Mo}$ ratio on the catalytic properties of Fe-Te-Mo-Ox catalyst at TBA oxidative amonolysis to MAN. Temperature is $643 \mathrm{~K}$, contact time is $2.4 \mathrm{~s}$, reaction conditions are given in Table 5 .

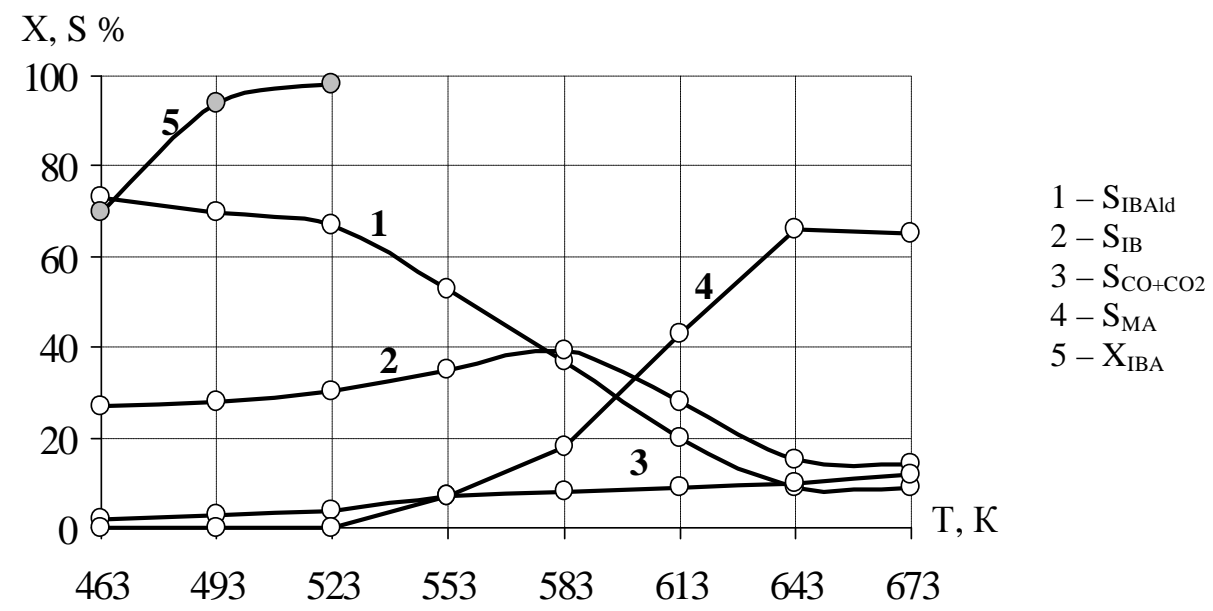

Fig. 5. Dependence of conversion (X) and selectivity (S) of IBA oxidation products over initial (non-promoted) Fe-Te-Mo-Ox catalyst upon temperature at $\tau_{\mathrm{k}}=2.4 \mathrm{~s}$ (flow reactor with stationary catalyst and impulse feed of reaction mixture ( $4 \mathrm{~mol} \%$ of IBA in the air); $V_{i m p}=12.5 \mathrm{~cm}^{3}, V_{f}=0.56 \mathrm{~cm}^{3} / \mathrm{s}$ )

Thus, three following rows represent barium promoter properties (isobutylene conversion is in brackets).

By the activity:

$\mathrm{BaCl}_{2}(98 \%)=\mathrm{Ba}\left(\mathrm{NO}_{3}\right)_{2}(98 \%)>\mathrm{BaSO}_{4}(78 \%)$.

By the selectivity of MAN formation:

$\mathrm{BaCl}_{2}(89 \%)>\mathrm{Ba}\left(\mathrm{NO}_{3}\right)_{2}(87 \%)>\mathrm{BaSO}_{4}(80 \%)$.

By MAN yield:

$\mathrm{BaCl}_{2}(87.2 \%)>\mathrm{Ba}\left(\mathrm{NO}_{3}\right)_{2}(85.2 \%)>\mathrm{BaSO}_{4}(62.4 \%)$.

Thus, the best catalyst by MAN yield is the catalyst promoted with $\mathrm{BaCl}_{2}(\mathrm{Ba} / \mathrm{Mo}=0.1)$.

If we compare isobutylene and TBA oxidative amonolysis over Fe-Te-Mo-Ox promoted with $\mathrm{Ba}\left(\mathrm{NO}_{3}\right)_{2}$ (see Table 2 and Fig. 3), we can see that MAN yields are practically the same (85.1 and $85.2 \%$ relatively). The MAN maximum yield $(87.2 \%)$ is achieved at TBA oxidative amonolysis over the catalyst promoted with $\mathrm{BaCl}_{2}$ at $643 \mathrm{~K}$ and $\tau_{k}=3.6 \mathrm{~s}$.
In addition to isobutylene and TBA, isobutyl alcohol (IBA) may be used for methacrylates obtaining. The IBA oxidation over initial Fe:Te:Mo $(1: 0.85: 1)$ catalyst is represented in Fig. 5.

We can see from Fig. 5 that IBA total conversion is achieved at $530 \mathrm{~K}$ and $\tau_{\mathrm{k}}=2.4 \mathrm{~s}$. Isobutyric aldehyde (IBAld), isobutylene and a small amount of $\mathrm{CO}+\mathrm{CO}_{2}$ $(3 \%)$ are the main products under mentioned conditions. The maximum selectivity by IBAld $(73 \%)$ is achieved at minimum investigated temperature $(463 \mathrm{~K})$ and the selectivity by isobutylene (39\%) - at $523 \mathrm{~K}$. MA is formed at temperature about $530 \mathrm{~K}$ due to isobutylene oxidation and IBAld oxidative dehydration. The selectivity by IBAld decreases and selectivity by MA increases till $66 \%$ with the temperature increase prior to $643 \mathrm{~K}$. At $673 \mathrm{~K}$ it slightly decreases (till $65 \%$ ) probably due to the $\mathrm{CO}+\mathrm{CO}_{2}$ afteroxidation. The yield of carbon oxides increases with the temperature increase. 
Table 5

Effect of $\mathrm{BaCl}_{2} / \mathrm{Mo}$ ratio on the catalytic properties of $\mathrm{Fe}$-Te-Mo-Ox catalyst at TBA oxidative amonolysis to MAN (concentrations at the inlet (mol \%): $\mathrm{TBA}-2 ; \mathrm{NH}_{3}-3 ; \mathrm{O}_{2}-5$ in helium)

\begin{tabular}{|c|c|c|c|c|c|c|c|}
\hline \multirow{2}{*}{$\begin{array}{c}\mathrm{BaCl}_{2} / \mathrm{Mo} \\
\text { ratio }\end{array}$} & \multirow[t]{2}{*}{$\tau_{k}$} & \multirow[t]{2}{*}{$\mathrm{T}, \mathrm{K}$} & \multirow[t]{2}{*}{$\mathrm{X}, \%$} & \multicolumn{3}{|c|}{ Selectivity by:, $\%$} & \multirow[t]{2}{*}{ MAN yield, $\%$} \\
\hline & & & & MA & MAN & $\mathrm{CO}_{2}$ & \\
\hline \multirow{12}{*}{$0.05\left(\mathrm{~K}_{1}\right)$} & \multirow{3}{*}{0.6} & 673 & 95.1 & 27.7 & 55.5 & 16.8 & 52.8 \\
\hline & & 643 & 70.4 & 44.3 & 48.2 & 7.5 & 33.9 \\
\hline & & 613 & 64.9 & 56.0 & 36.5 & 7.5 & 23.7 \\
\hline & \multirow{3}{*}{1.2} & 673 & 96.6 & 12.3 & 59.0 & 28.7 & 57.0 \\
\hline & & 643 & 86.9 & 27.1 & 55.7 & 17.2 & 48.4 \\
\hline & & 613 & 80.3 & 36.3 & 51.5 & 12.2 & 41.3 \\
\hline & \multirow{3}{*}{2.4} & 673 & 98.1 & 6.2 & 63.0 & 30.8 & 61.9 \\
\hline & & 643 & 90.0 & 16.8 & 61.0 & 22.2 & 54.9 \\
\hline & & 613 & 85.5 & 32.4 & 51.5 & 16.1 & 44.0 \\
\hline & \multirow{3}{*}{3.6} & 673 & 98.4 & 4.0 & 63.8 & 32.2 & 62.7 \\
\hline & & 643 & 98.0 & 15.7 & 70.3 & 14.0 & 68.9 \\
\hline & & 613 & 97.8 & 23.5 & 63.5 & 13.0 & 62.1 \\
\hline \multirow{9}{*}{$0.1\left(\mathrm{~K}_{2}\right)$} & \multirow{3}{*}{1.2} & 673 & 90.0 & 3.8 & 86.3 & 9.9 & 77.7 \\
\hline & & 643 & 86.7 & 8.0 & 84.8 & 7.2 & 73.5 \\
\hline & & 613 & 79.6 & 8.5 & 84.8 & 6.7 & 67.5 \\
\hline & \multirow{3}{*}{2.4} & 673 & 98.4 & 2.7 & 84.4 & 12.9 & 83.0 \\
\hline & & 643 & 94.0 & 2.9 & 89.4 & 7.7 & 84.0 \\
\hline & & 613 & 85.5 & 4.6 & 88.6 & 6.8 & 75.7 \\
\hline & \multirow{3}{*}{3.6} & 673 & 98.6 & 0.3 & 85.7 & 16.0 & 82.5 \\
\hline & & 643 & 98.0 & 2.0 & 89.0 & 9.0 & 87.2 \\
\hline & & 613 & 97.8 & 4.0 & 87.2 & 8.8 & 85.3 \\
\hline \multirow{12}{*}{$0.2\left(\mathrm{~K}_{3}\right)$} & \multirow{3}{*}{0.6} & 673 & 80.9 & 12.0 & 72.7 & 15.3 & 58.8 \\
\hline & & 643 & 71.0 & 13.0 & 74.8 & 12.2 & 53.1 \\
\hline & & 613 & 48.7 & 14.9 & 74.1 & 11.0 & 36.0 \\
\hline & \multirow{3}{*}{1.2} & 673 & 86.7 & 7.0 & 75.7 & 17.3 & 65.6 \\
\hline & & 643 & 80.0 & 8.0 & 79.1 & 12.9 & 63.3 \\
\hline & & 613 & 78.3 & 8.7 & 79.5 & 11.8 & 62.2 \\
\hline & \multirow{3}{*}{2.4} & 673 & 98.6 & 1.6 & 71.1 & 27.3 & 70.1 \\
\hline & & 643 & 98.1 & 5.0 & 80.0 & 15.0 & 78.5 \\
\hline & & 613 & 97.5 & 7.0 & 80.7 & 12.3 & 78.7 \\
\hline & \multirow{3}{*}{3.6} & 673 & 99.5 & 1.2 & 66.0 & 32.8 & 65.7 \\
\hline & & 643 & 99.5 & 2.0 & 71.1 & 26.9 & 70.7 \\
\hline & & 613 & 98.9 & 3.0 & 82.9 & 14.1 & 82.0 \\
\hline \multirow{12}{*}{$0.5\left(\mathrm{~K}_{4}\right)$} & \multirow{3}{*}{0.6} & 673 & 80.6 & 9.5 & 82.0 & 8.5 & 66.1 \\
\hline & & 643 & 71.8 & 10.3 & 83.1 & 6.6 & 59.7 \\
\hline & & 613 & 69.2 & 13.7 & 81.2 & 5.1 & 56.2 \\
\hline & & 673 & 84.1 & 4.5 & 78.1 & 17.4 & 65.7 \\
\hline & 1.2 & 643 & 80.2 & 9.5 & 78.0 & 12.5 & 62.6 \\
\hline & & 613 & 79.6 & 12.5 & 80.2 & 7.3 & 63.8 \\
\hline & & 673 & 98.1 & 1.5 & 73.6 & 24.9 & 72.2 \\
\hline & 2.4 & 643 & 92.5 & 4.2 & 75.7 & 20.1 & 70.0 \\
\hline & & 613 & 90.5 & 4.2 & 84.7 & 11.1 & 76.6 \\
\hline & & 673 & 99.5 & 0.7 & 72.7 & 26.6 & 72.3 \\
\hline & 3.6 & 643 & 95.4 & 2.0 & 75.8 & 22.2 & 72.3 \\
\hline & & 613 & 95.0 & 2.5 & 82.4 & 15.1 & 78.3 \\
\hline
\end{tabular}

Note: $\mathrm{X}_{\mathrm{TBA}}$ in all cases equals to $100 \%$

Thus obtained results show that $i-\mathrm{C}_{4} \mathrm{H}_{8}$ and IBAld are present in the reaction products which may be transformed into MA with further transformation into MAN in the presence of $\mathrm{NH}_{3}$ in the mixture.

\subsection{IBA Oxidative Amonolysis into MAN}

The results of IBA oxidative amonolysis over Fe-Te-Mo-Ox catalyst are represented in Fig. 6.
One can see from Fig. 6 that $i$ - $\mathrm{C}_{4} \mathrm{H}_{8}$, IBAld, MA, the small amount of MAN and $\mathrm{CO}+\mathrm{CO}_{2}$ are the reaction products at low temperatures. The total conversion of IBA takes place at all investigated temperatures and $i-\mathrm{C}_{4} \mathrm{H}_{8}$ - at $613 \mathrm{~K}$. The maximum selectivity by MA $(60 \%)$ is achieved at $613 \mathrm{~K}$. The increase of temperature from 583 to $703 \mathrm{~K}$ increases the selectivities by MAN and $\mathrm{CO}+\mathrm{CO}_{2}$. The selectivity by MA gradually decreases at temperatures 
above $613 \mathrm{~K}$. The maximum selectivity by MAN (62\%) is achieved at $703 \mathrm{~K}$. Under such conditions a great amount of unreacted MA (30\%) and $\mathrm{CO}+\mathrm{CO}_{2}(10 \%)$ is in the reaction products. The comparison of IBA oxidation and oxidative amonolysis (Figs. 5 and 6) show that $\mathrm{NH}_{3}$ presented in the mixture hinders the formation of total oxidation products. At $673 \mathrm{~K}$ and $\tau_{\mathrm{k}}=2.4 \mathrm{~s}$ the selectivity by $\mathrm{CO}+\mathrm{CO}_{2}$ is $13 \%$ in the oxidation reaction (Fig. 5) and $6 \%$ in the oxidative amonolysis reaction (Fig. 6).

Thus, MAN yield over non-promoted catalyst is relatively low $(60 \%)$ and in the reaction products there is a plenty of unreacted MA (29\%) which is necessary to be returned to the reactor inlet. The increase of contact time at $703 \mathrm{~K}$ decreases the selectivity by MA and MAN due to their afteroxidation to $\mathrm{CO}+\mathrm{CO}_{2}$.

As we mentioned above, potassium and barium salts improve catalytic properties of $\mathrm{Fe}-\mathrm{Te}-\mathrm{Mo}-\mathrm{Ox}$ at isobutylene oxidation and oxidative amonolysis. Therefore, it was advisable to study their effects on the efficiency of the catalyst at IBA oxidative amonolysis.

The investigation of $\mathrm{K}_{2} \mathrm{SO}_{4}$ effect on the catalytic properties of Fe-Te-Mo-O $\mathrm{O}_{\mathrm{x}}$ at the oxidative amonolysis shows that the catalyst with $\mathrm{K}_{2} \mathrm{SO}_{4}^{\mathrm{x}} / \mathrm{Mo}=0.2$ is the best by MAN and MA+MAN yields. At smaller concentrations there is a plenty of unreacted isobutylene and IBAld. At higher concentrations $\left(\mathrm{K}_{2} \mathrm{SO}_{4} / \mathrm{Mo}=0.5\right)$ there is a plenty of metacrolein. The effect of temperature at contact time of $3.6 \mathrm{~s}$ on the isobutylene conversion (IBA conversion in all cases is $100 \%$ ) and the selectivity by reaction products over optimal catalyst $\left(\mathrm{K}_{2} \mathrm{SO}_{4} / \mathrm{Mo}=0.2\right)$ is represented in Fig. 7.

One can see from Fig. 7 that isobutylene, MA, MAN and $\mathrm{CO}+\mathrm{CO}_{2}$ are reaction products. IBA and IBAld are absent in the reaction products, hence their conversions are $100 \%$. The increase of temperature decreases the selectivity by MA and proportionally increases the selectivity by MAN. It means that MA is an intermediate product of MAN formation and IMAld is changed into MA via oxidative dehydration [12]. The temperature of $673 \mathrm{~K}$ and contact time of $3.6 \mathrm{~s}$ are the process optimal conditions, under which IBA conversion is $100 \%$, isobutylene conversion is $98 \%$, the selectivity by MAN is $63 \%$ and by MA $-20 \%$. The total yield of particular oxidation products is $83 \%$. MAN yield is $61.7 \%$ (to calculate for reacted isobutylene).

We also investigated the promotion of Fe-Te-Mo-Ox catalyst with $\mathrm{BaSO}_{4}$ and $\mathrm{BaCl}_{2}$ at IBA oxidative amonolysis. The effect of $\mathrm{BaSO}_{4} / \mathrm{Mo}$ ratio on the isobutylene conversion (IBA conversion is $100 \%$ ) and the selectivity by IBAld, MA, MAN and $\mathrm{CO}+\mathrm{CO}_{2}$ is represented in Fig. 8.

One can see from Fig. 8 that maximum selectivity by MAN (61\%) under mentioned conditions is achieved over the catalyst with $\mathrm{BaSO}_{4} / \mathrm{Mo}=0.1$. Isobutylene conversion decreases from 95 to $67.5 \%$ with the increase of promoter concentration (from $\mathrm{BaSO}_{4} / \mathrm{Mo}=0.05$ to
$\mathrm{BaSO}_{4} / \mathrm{Mo}=0.5$ ). Thus, promoter blocks centres of total, as well as partial oxidation.

The effect of temperature on the IBA oxidative amonolysis over thecatalyst with $\mathrm{BaSO}_{4} / \mathrm{Mo}=0.1$, which is optimal by MAN selectivity, is represented in Fig. 9.

Within the temperature range from 583 to $673 \mathrm{~K}$ isobutylene conversion increases from 70.7 to $87.1 \%$, the selectivity by MAN increases from 36.3 to $68.9 \%$ and the selectivity by MA has the maximum $(20.6 \%)$ at $\mathrm{T}=613 \mathrm{~K}$. The selectivity by IBAld decreases from 48.5 to $5.8 \%$. The yield by MAN increases from 36.3 to $68.9 \%$ and from 25.7 to $60 \%$ if we calculate by isobutylene. IBA conversion is $100 \%$ at all temperatures. The yield by $\mathrm{MAN}+\mathrm{MA}$ is $71.8 \%$, the selectivity by $\mathrm{CO}+\mathrm{CO}_{2}$ is $11.0 \%$.

The catalyst promoted with $\mathrm{BaCl}_{2}$ has the optimal selectivity by $\mathrm{MAN}$ at the ratio $\mathrm{BaCl} / \mathrm{Mo}=0.1$ (analogously to the catalyst promoted with $\mathrm{BaSO}_{4}$ ). The catalytic properties of this catalyst at different temperatures and contact time of $3.6 \mathrm{~s}$ are represented in Fig. 10.

It has been established that within the temperature range from 583 to $673 \mathrm{~K}$ isobutylene conversion increases from 87 to $100 \%$. The selectivity by MAN increases from 52 to $72 \%$ and the selectivity by MA decreases from 42 to $20 \%$. The selectivity by $\mathrm{CO}+\mathrm{CO}_{2}$ increases from 6 to $8 \%$. IBAld is absent in the reaction products.

As it was mentioned above and in [5, 12], MA and IBAld are intermediate products which form MAN and MA, respectively and in industry it is necessary to return them to the reactor inlet in case of their partial conversion.

The comparison of promoter activity over Fe-Te-Mo-Ox catalysts at IBA oxidative amonolysis at $673 \mathrm{~K}$ and $\tau_{k}=3.6 \mathrm{~s}$ shows the following regularities.

By isobutylene conversion:

$\mathrm{K}_{0}(100) \geq \mathrm{BaCl}_{2}(100)>\mathrm{K}_{2} \mathrm{SO}_{4}(98)>\mathrm{BaSO}_{4}(87)$.

By the selectivity by MAN formation:

$\mathrm{BaCl}_{2}(72)>\mathrm{BaSO}_{4}(69)>\mathrm{K}_{2} \mathrm{SO}_{4}(63)>\mathrm{K}_{0}(62)$.

By the selectivity by MA formation under optimal conditions for MAN yield:

$\mathrm{K}_{0}(33)>\mathrm{K}_{2} \mathrm{SO}_{4}(24)>\mathrm{BaCl}_{2}(20)>\mathrm{BaSO}_{4}(13)$.

By MAN yield:

$\mathrm{BaCl}_{2}(72)>\mathrm{K}_{2} \mathrm{SO}_{4}(61.7)>\mathrm{BaSO}_{4}(60)=\mathrm{K}_{0}(60)$.

Thus, the best catalyst by MAN yield is the catalyst promoted with $\mathrm{BaCl}_{2}$. The optimal conditions of IBA oxidative amonolysis are: $\mathrm{T}=673 \mathrm{~K}, \tau_{k}=3.6 \mathrm{~s}$, concentration of IBA in the air $4 \mathrm{~mol} \%, \mathrm{NH}_{3}-6 \mathrm{~mol} \%$. Under these conditions isobutylene and IBA conversions are $100 \%$, the selectivity by MA is $20 \%$, by MAN $72 \%$, MAN yield is $72 \%$.

The comparative analysis of the results obtained at isobutylene, TBA and IBA oxidative amonolysis shows that MAN maximum yield $(87.2 \%)$ is obtained over the catalyst promoted with $\mathrm{BaCl}_{2}(\mathrm{Ba} / \mathrm{Mo}=0.1)$. Practically the same MAN yields (85.2 and $85.1 \%$ ) are achieved at TBA and isobutylene oxidative amonolysis over the catalyst promoted with $\mathrm{Ba}\left(\mathrm{NO}_{3}\right)_{2}$. The less MAN yield (72\%) is achieved at IBA amonolysis. 
$\mathrm{S} \%$

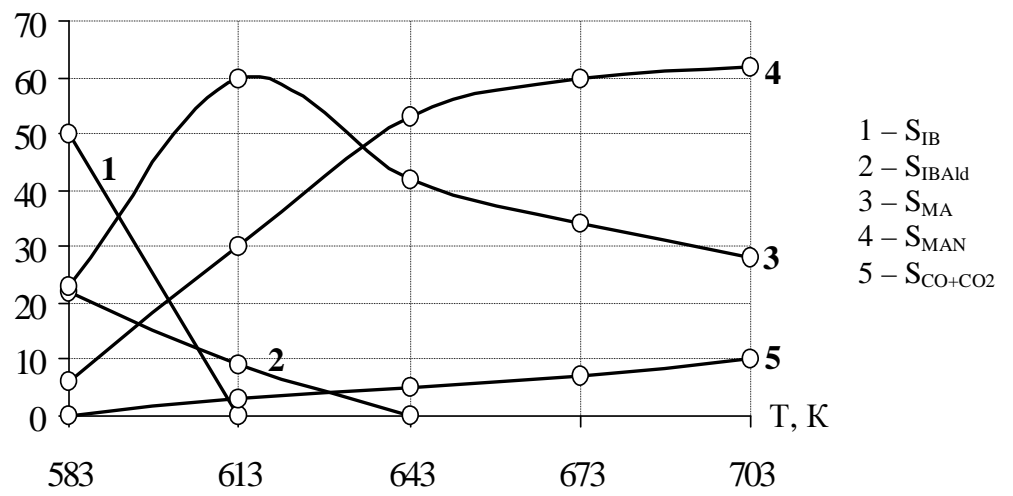
$\mathrm{X}, \mathrm{S} \%$
$\mathrm{S} \mathrm{CO}+\mathrm{CO}_{2}, \%$

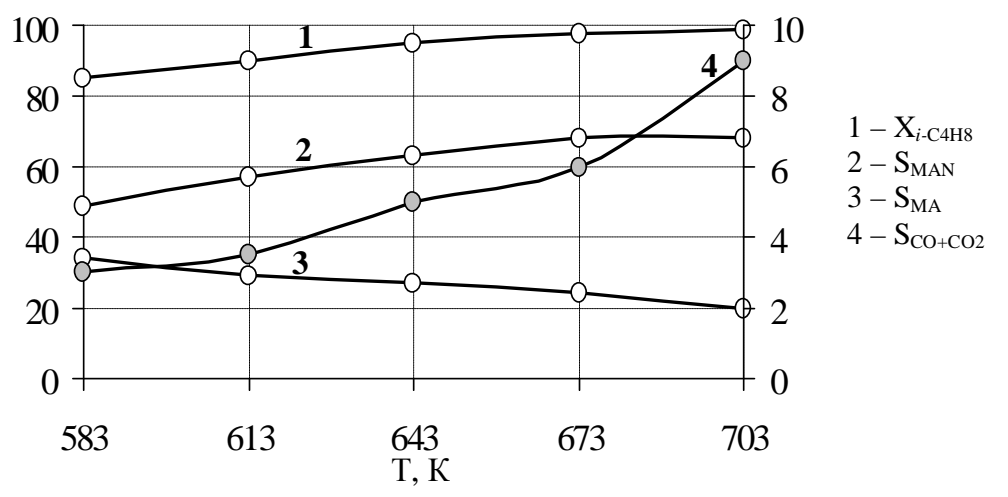

Fig. 6. Dependence of the selectivity of IBA oxidative amonolysis products over initial (non-promoted) Fe-Te-

Mo-Ox catalyst upon temperature at $\tau_{k}=2.4 \mathrm{~s}$ (flow reactor with stationary catalyst and impulse feed of reaction

mixture $(4 \mathrm{~mol} \%$ of IBA and $6 \mathrm{~mol} \%$ of $\mathrm{NH}_{3}$ in the air); $V_{\text {imp }}=12.5 \mathrm{~cm}^{3}, V_{f}=0.56 \mathrm{~cm}^{3} / \mathrm{s}$ )

Fig. 7. Effect of temperature at $\tau_{\mathrm{k}}=3.6 \mathrm{~s}$ on the conversion and the selectivity by IBA oxidative amonolysis products over Fe-Te-Mo-Ox catalyst promoted with $\mathrm{K}_{2} \mathrm{SO}_{4}\left(\mathrm{~K}_{2} \mathrm{SO}_{4} /\right.$ $\mathrm{Mo}=0.2)$. Reaction conditions are given in Fig. 6

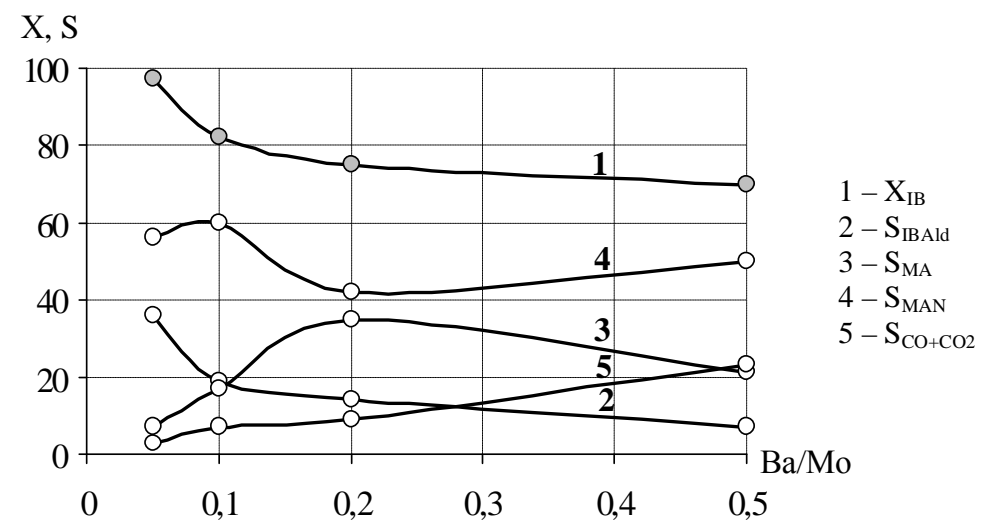

\section{$\mathrm{X}, \mathrm{S} \%$}

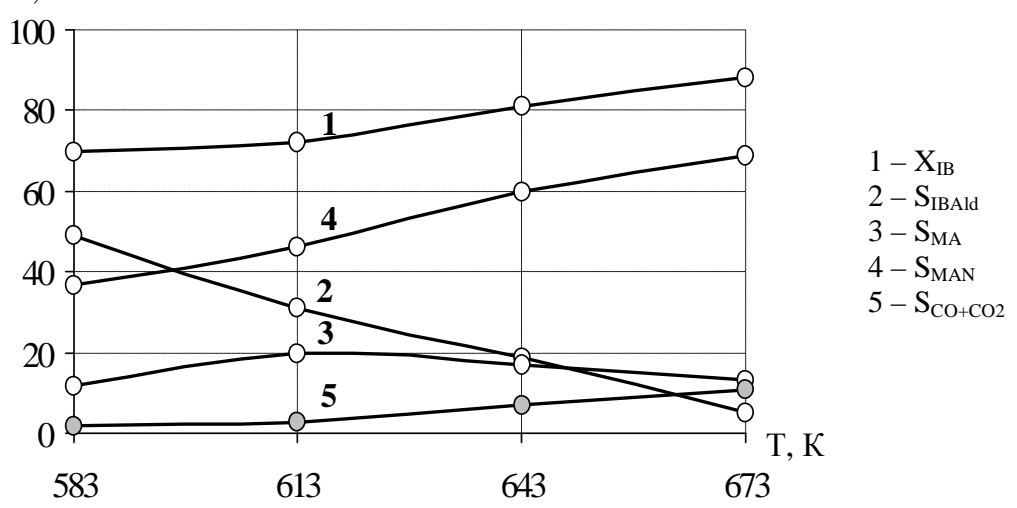

Fig. 8. Dependence of isobutylene conversion and the selectivity by obtained products upon promoter concentration at IBA oxidative amonolysis over Fe-Te-Mo-Ox catalyst promoted with $\mathrm{BaSO}_{4}$ $\left(\mathrm{T}=643 \mathrm{~K}, \tau_{\mathrm{k}}=2.4 \mathrm{~s}\right)$. Reaction conditions are given in Fig. 6

Fig. 9. Dependence of isobutylene conversion and the selectivity by obtained products upon temperature at IBA oxidative amonolysis over Fe-TeMo-Ox catalyst promoted with $\mathrm{BaSO}_{4}\left(\mathrm{BaSO}_{4} / \mathrm{Mo}=0.1\right.$, $\left.\tau_{\mathrm{k}}=2.4 \mathrm{~s}\right)$. Reaction conditions are given in Fig. 6 


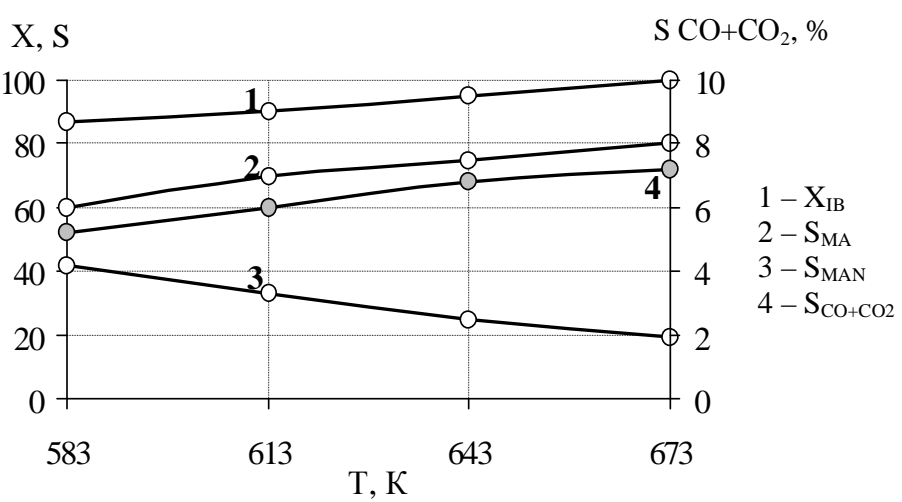

Fig. 10. Dependence of isobutylene conversion and the selectivity by obtained products upon temperature at IBA oxidative amonolysis over Fe-Te-Mo-Ox catalyst promoted with $\mathrm{BaCl}_{2}$

$\left(\mathrm{BaCl}_{2} / \mathrm{Mo}=0.1, \tau_{\mathrm{k}}=3.6 \mathrm{~s}\right)$. Reaction conditions are given in Fig. 2

\section{Conclusions}

Isobutylene, tert-butyl and isobutyl alcohols oxidative amonolysis reactions have been investigated over Fe:Te:Mo (1:0.85:1) oxide catalysts promoted with potassium, magnesium and barium salts. Optimal atomic ratio between the promoter and molybdenum for corresponding initial raw material has been established. Optimal conditions for various processes have been determined.

It has been shown that at TBA oxidative amonolysis MAN maximum yield (87.2\%) is achieved over Fe:Te:Mo (1:0.85:1) oxide catalyst promoted with $\mathrm{BaCl}_{2}(\mathrm{Ba} / \mathrm{Mo}=$ $=0.1)$ at $\mathrm{T}=643 \mathrm{~K}$ and $\tau_{\mathrm{k}}=3.6 \mathrm{~s}$. The inlet concentration $(\mathrm{mol} \%)$ is: TBA $-2, \mathrm{NH}_{3}-3, \mathrm{O}_{2}-5$. Under these conditions TBA conversion is $100 \%$, isobutylene conversion - $98 \%$, the selectivity by MAN - $89 \%$, by $\mathrm{MA}-2 \%$, by $\mathrm{CO}+\mathrm{CO}_{2}-9 \%$.

Oxidative amonolysis of alternative raw material IBA was carried out over the catalyst promoted with $\mathrm{BaCl}_{2}$ $(\mathrm{Ba} / \mathrm{Mo}=0.1)$ at $\mathrm{T}=643 \mathrm{~K}$ and $\tau_{\mathrm{k}}=3.6 \mathrm{~s}$. The inlet concentration $(\mathrm{mol} \%)$ : IBA $-4, \mathrm{NH}_{3}-6$. Under these conditions IBA conversion is $100 \%$, isobutylene conversion $-100 \%$, the selectivity by MAN - $72 \%$, by $\mathrm{MA}-20 \%$, by $\mathrm{CO}+\mathrm{CO}_{2}-8 \%$.

\section{References}

[1] Lebedev N.: Khimiya I technologiya osnovnogo organicheskogo I neftekhimicheskogo sinteza. Khimiya, Moskwa 1988.

[2] Zhyznevskiy V.: D.Sc. thesis, Lviv 1982.

[3] Gyznevskiy V., Gumenetskiy V., Bagan L. and Majkova S.: J. Phys. Khimii, 2001, 75, 1782.

[4] Gyznevskiy V., Fedevych E. and Tolopko D.: J. Prykl. Khimii, 1971, 4, 846.

[5] Dvonchova E.: PhD thesis, Lviv 1988.

[6] Gyznevskiy V., Gumenetskiy V., Bagan L. and Majkova S.: Praci Nauk. Tovarystva Shevchenka, 2003, X, 103.

[7] Boreskov G.: Kinetika i kataliz, 1970, 1, 5.

[8] Ai M.: J. Catalysis, 1978, 1, 16.

[9] Burrington I., Kartisek C. and Grasselli R.: J. Catal., 1980, 1, 235.

[10] Ghenassia E. and Germain I.: Bull. Soc. Chem. France, 1975, 3-4, 731.

[11] Nikolskiy B. (Ed.): Spravochnik khimika, 1971, 2.

[12] Gyznevskiy V., Gumenetskiy V., Khlibishyn Yu. and Moshkovska I.: Khim. Prom. Ukrainy, 2004, 6, 27.

\section{ОДЕРЖАННЯ МЕТАКРИЛОНТРИЛУ ОКИСНЮВАЛЬНИМ АМОНОЛЗОМ ІЗОБУТИЛЕНУ, ТРЕТ.-ТА ІЗО-БУТИЛОВОГО СПИРТІВ}

Анотація. Досліджено процес одержання метакрилонітрилу окиснювальним амонолізом на різних складних оксидних каталізаторах та пошук альтернативної ізобутилену сировини для синтезу МАН.

Ключові слова: каталіз, метакрилонітрил, каталізатор, промотор. 